\title{
Study of chemical bond strength of methyl methacrylate (MMA) based bonding agent on type I dentin collagen at various humidity
}

\author{
Adioro Soetojo \\ Department of Conservative Dentistry \\ Faculty of Dentistry Airlangga University \\ Surabaya - Indonesia
}

\begin{abstract}
One of the basic agents used in dentin bonding solution is methyl methacrylate (MMA). This bonding agent is widely used in dentistry. It have been proved that the adhesion between dentin bonding agent and collagen fibril is chemically bond; though the chemical bonding contribution is smaller than physical mechanical bond. The purpose of the research was to examined the chemical bonding strength of MMA based dentin bonding on type I dentin collagen at various humidity. Samples of treatment group were put into desiccator with 60\%, 70\%, 80\%, and 90\% humidity, while for control groups at room humidity (65\%). Chemical bond of pure MMA and MMA mixed with collagen were measured by FTIR. The lower the value of MMA carbonyl, the higher absorbance band speak of chemical bond strength between MMA and collagen. Data was statistically analyzed with One-Way ANOVA at 95\% confidence level continued with Tukey-HSD test. The result showed that the highest chemical bond strength was at $65 \%$ humidity ( $p \leq 0.05)$. In conclusion, many esther carbonyl MMA molecules reacted with amino collagen at 65\% humidity. This can be shown by the lowest peak's value of the MMA carbonyl absorbance at FTIR.
\end{abstract}

Key words: FTIR, humidity, MMA, type I dentin collagen, carbonyl group

Correspondence: Adioro Soetojo, c/o: Bagian Konservasi Gigi, Fakultas Kedokteran Gigi Universitas Airlangga. Jl. Mayjend. Prof. Dr. Moestopo 47 Surabaya 60132, Indonesia.

\section{INTRODUCTION}

Science development of operative dentistry made bonding agents have been used excessively to restore dental caries. These agents are ideal to restore class $\mathrm{V}$ erosion which involving dentin, especially for the elderly patients. Since the bonding agents have hydrophilic characteristic, it can adhere well to dentin., ${ }^{1,2,3}$ Recently there are many bonding agents with hydrophilic and hydrophobic characteristic have been produced; such as bisphenyl dimethacrylate (BPDM), 4-methacryloxyethyl trimellitic anhydride (4-META) and others.

Bonding agents with hydrophilic characteristic will adhere to dentin collagen, while the one hydrophobic characteristic adhere on composite resin. ${ }^{3,4}$ Good wetting characteristics of bonding agents due to their low viscosity which increase surface energy. Surface energy is the potency of an agent surface to pull another substance surface. The adhesion between two agents occur if there is adhesive force at the interface area. The increase energy of each unit area is related with surface energy and surface tension. ${ }^{3}$ There are several monomer bonding agents available such as hydroxyethyl methacrylate (HEMA), BPDM, glutaraldehyde, 4-META, methyl methacrylate (MMA), etc. In order to make clinical application easier, usually the bonding agent is added with photo-initiator (camphoroquinone) which absorb the blue region of visible light spectrum at the wave-length from 400 to $500 \mathrm{~nm} .^{3,6}$ Accelerators from amine groups, which well interact with camphoroquinone such as dimethylaminoethyl methacrylate $0.15 \%$, are often added to bonding agents. For long storage, the bonding agent is added with inhibitor agent, butylated hydroxytoluene $0.01 \%$.

The adhesion of bonding agent on dentin surface occurs physical-mechanically or chemically. The physicalmechanical bonding is caused by penetration of bonding agent into nano space of collagen fibrils; resin penetration in dentin tubules; microscopically retention on dentin surface (undercut, crack, micro space) and Vander-Waals force based on dipolar attraction. ${ }^{2,3,4}$ Chemical bonding is caused by interaction of esther carbonyl groups of dentin bonding with amine groups at collagen which produce amide groups $[\mathrm{C}(\mathrm{O}) \mathrm{NH}]$. This bonding is strong due to of its covalent characteristics called as inter-atomic primer bond. ${ }^{7}$ The bonding process of restoration materials on dental structure are a complex matter including MMA based resin bonding. The resin bonding failure are caused by some factors, such as smear layer on dental surface, topical application of fluoride, unhomogeneous tooth composition (organic and inorganic agents are very different in enamel and dentin), and saliva or blood contamination.

Dentin is life tissues which containing approximately $60 \%$ inorganic components (hydroxyapatite) $\mathrm{C}_{\mathrm{a} 10}\left(\mathrm{PO}_{4}\right) 6$ $(\mathrm{OH})_{2} ; 30 \%$ organic components and $10 \%$ water. Those 
organic components are $90 \%$ collagen, and $10 \%$ noncollagenous. Most of those collagens are type I and few of them are type $\mathrm{V} .{ }^{9}$ Type I collagen which frequently used as research agent are a sequence of amino acid: prolin, prolin, glisin $\left.\left\{\mathrm{H}_{2} \mathrm{~N} \text {-(pro-pro-gly) }\right)_{5}-\mathrm{COOH}\right\} .{ }^{10,11}$ Dentin bonding can bond well to collagen fibril if the collagen is in active or permeable condition. The permeability of collagen is highly influenced by humidity of dentin surface. If the humidity is too high or too low, the bonding agent will hardly bonds on collagen fibril. Therefore, it requires optimum humidity condition to obtained a maximum bond of resin bonding agent to collagen. ${ }^{5}$

The humidity used in the research were in the range of 60 to $90 \%$. The other factors that influence the bond of dentin bonding to collagen are viscosity, type and concentration of dentin bonding agents, application of acid agents as conditioner and temperature of surrounding collagen. ${ }^{12-15}$ This research used resin monomer MMA $\mathrm{C}_{5} \mathrm{H}_{8} \mathrm{O}_{2}$. The MMA solution is a clear and transparent liquid at room temperature. The physical characteristics as follows: melting point at $-48^{\circ} \mathrm{C}$, boilling point at $100,8^{\circ} \mathrm{C}$, density $=0,945 \mathrm{~g} / \mathrm{ml}\left(20^{\circ} \mathrm{C}\right)$, heat of polymerization $=12,9 \mathrm{kcal} / \mathrm{mol}^{3}$

The aim of the research was to examined the chemical bond strength of MMA based bonding on type I dentin collagen at various humidity.

\section{MATERIAL AND METHODS}

Material which were used: bovine type I collagen (Sigma Chemical, St. Louis, USA; batch \# 031K7054), methyl methacrylate liquid (Vertex; Dentimex, Holland). Instruments which were used: desiccators with vacuum faucet (DSC, China), hygrometer (Haar. Synth-Hygro, Germany), air suction (Schuco, USA), micro injection (Hamilton, USA), Fourier Transformed Infra Red instrument (FTIR, Jasco FT/IR 5300, Japan).

The research was conducted in Laboratorium Dasar Bersama (LDB) Airlangga University with room humidity of $65 \%$ and room temperature at $25 \pm 2{ }^{\circ} \mathrm{C}$. The method of this research has been presented in detail in a previous research. ${ }^{17}$ To arrange $90 \%$ of humidity, $150 \mathrm{cc}$ water were put in the bottom part of desiccators, then calibrated hygrometer was set. In this condition, the humidity seen from hygrometer was 94-95\%. Then from faucet located above desiccators, the air is pumped out with air suction until humidity reached to $90 \%$ and the pump directly closed. For $80 \%$ humidity, the air in desiccators is pumped out until humidity reached to $80 \%$. In order to fasten the work, we put the silica gel which is activied first in to desiccators. Afterwards the air was pumped out until the humidity in desiccators reached to $60 \%$.

To prepared kalium bromide $(\mathrm{KBr})$ pellets: $300 \mathrm{mg}$ $\mathrm{KBr}$ powder were dropped with $10 \mu \mathrm{l}$ MMA (9.45 mg of weight) using micro-injection. Molecular weight of MMA was $0.945 \mathrm{~g} / \mathrm{ml}$. Total weight of $\mathrm{KBr}$ powder and MMA were $309.45 \mathrm{mg}$, then all of the materials were crushed with mortar and pestle made from agate stone. After mixed, $50 \mathrm{mg}$ mixed-powder were put in to $\mathrm{KBr}$ die and compressed until 10 ton while it's was vacuumed. The final result of the process was a clear pellet. The pellets were observed into FTIR.

To prepared collagen-MMA mixture, $2 \mathrm{mg}$ collagen were dropped with $10 \mu \mathrm{l}$ MMA (9.45 mg of weight) and $\mathrm{KBr}$ powder were added with until the weight were $309.45 \mathrm{mg}$. The mixed powders were compressed, and then $50 \mathrm{mg}$ of the mixtures were put it in to $\mathrm{KBr}$ die. Next, the samples are compressed until 10 ton while it has been vacuumed. That pellets were finally observed in to FTIR.

To make samples at various humidity: $2 \mathrm{mg}$ collagen fibers were packed into desiccators with hygrometer that has been calibrated. Then the humidity of desiccators were arranged to $60 \%, 70 \%, 80 \%$, and $90 \%$. As soon as release from the desiccators, the collagen was dropped with MMA and added with $\mathrm{KBr}$ powder until reached 309, $45 \mathrm{mg}$ of weight. The mixed powders were compressed, and then $50 \mathrm{mg}$ of the mixtures were put it in to $\mathrm{KBr}$ die. Next, the samples are compressed until 10 ton while it has been vacuumed. The peak of carbonyl absorbance band $(\mathrm{C}=0)$ of treatment groups and control groups was measured. The method to calculate the peak of carbonyl (P) absorbance band as below. ${ }^{18}$

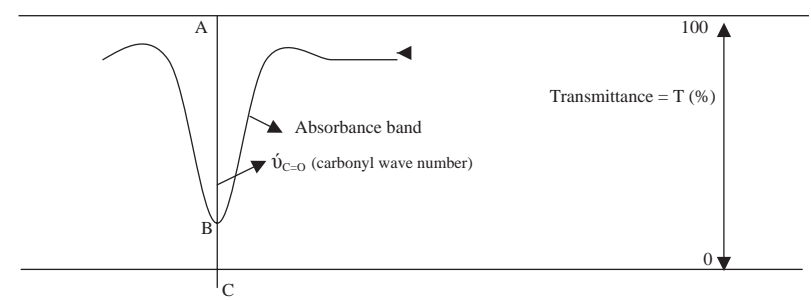

Figure 1. Peak of the MMA carbonyl absorbance band. Description:

$\mathrm{P}=(\mathrm{BC} / \mathrm{AB}) \times 100 ;(\mathrm{AB}$ and $\mathrm{BC}$ measured in centimeter). The calculation is accurately enough and trustworthy if the intensity of absorbance band at transmittance, $\mathrm{T}=30 \%$ to $60 \%$. 


\section{RESULTS}

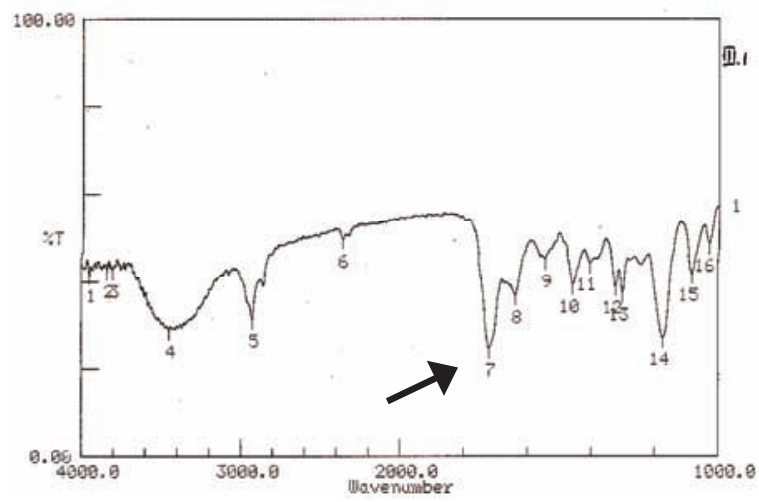

Figure 2. The IR ray spectrum of MMA and collagen $(\mathrm{KBr}$ pellets).

Value of the peak carbonyl absorbance band is 33,3; point 7 (arrow).

Humidity: $80 \%$.

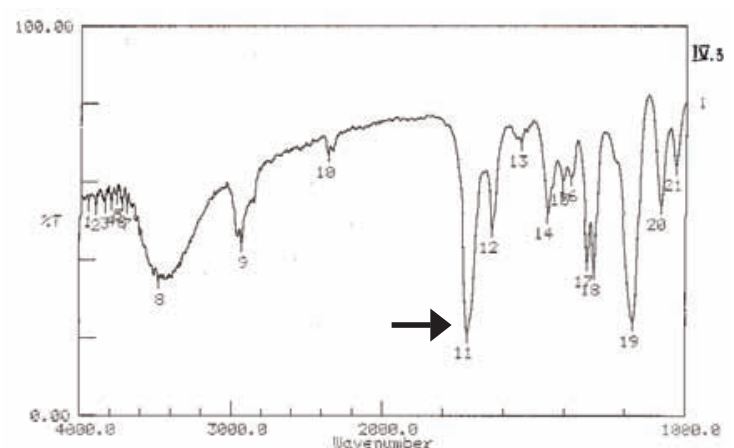

Figure 3. The IR ray spectrum of MMA + collagen $(\mathrm{KBr}$ pellets).

Value of the peak carbonyl absorbance band is 29,2; point 11 (arrow)

Humidity: $90 \%$.

Chemical bond measurement is done by using $\mathrm{KBr}$ pellets in which then irradiated by the IR ray. After that the peak value of the MMA esther carbonyl absorbance band was recorded. When MMA carbonyl groups excessively bond toward collagen amino groups, the peak value of the MMA carbonyl absorbance band decreased. The more MMA carbonyl groups bond with amino collagen groups the bond between those agents will increase. Mean value of MMA carbonyl absorbance band and standard deviation were shown at Table 1.

Mean value of the MMA carbonyl absorbance was $48.7 \pm 3.7$ then decreased at $60 \%, 65 \%, 70 \%, 80 \%$, and $90 \%$ humidity. To know whether the chemical bond data was normal, one sample of Kolmogorov Smirnov test was done. The $\mathrm{p}$ value at the experimental groups at $60-90 \%$ humidity showed the higher number than 0.05 ( $p>0.05)$. It means that the data of chemical bonds experimental groups at 60-90\% humidity were normal. To know the homogeneity of experimental groups, homogeneity of variance test was done. The result showed that the value of $p$ was 0.179
( $p>0.05)$. It means that the experiment of chemical bonds groups at 60-90\% humidity was homogen.

Table 1. Mean of the peak of MMA carbonyl absorbance and standard deviation at various humidity

\begin{tabular}{lrrc}
\hline \multicolumn{1}{c}{ Humidity } & $\mathrm{N}$ & $\overline{\mathrm{X}}$ (mean) & \multicolumn{1}{c}{ SD } \\
\hline MMA & 5 & 48.7200 & 3.73992 \\
$60 \%$ & 5 & 27.3600 & 2.21314 \\
$65 \%$ (control) & 5 & 19.1800 & 1.74557 \\
$70 \%$ & 5 & 20.5000 & 1.33791 \\
$80 \%$ & 5 & 30.9400 & 1.56301 \\
$90 \%$ & 5 & 34.5000 & 3.09031 \\
\hline
\end{tabular}

Description:

$\mathrm{N}=$ Amount of sample; $\overline{\mathrm{X}}=$ Mean of the peak of the MMA carbonyl absorbance band; SD $=$ Standart Deviation.

Table 2. The Tukey-HSD test in carbonyl absorbance band of MMA at various humidity

\begin{tabular}{|c|c|c|}
\hline \multicolumn{2}{|c|}{ Dentin bonding agent based on MMA } & \multirow{2}{*}{$\begin{array}{c}\text { Significance level } \\
21.360 *\end{array}$} \\
\hline MMA & $60 \%$ humidity & \\
\hline & $65 \%$ & $29.540 *$ \\
\hline & $70 \%$ & $28.220 *$ \\
\hline & $80 \%$ & $17.780 *$ \\
\hline & $90 \%$ & $14.220 *$ \\
\hline \multirow[t]{5}{*}{$60 \%$ humidity } & MMA & $-21.360 *$ \\
\hline & $65 \%$ & $8.180^{*}$ \\
\hline & $70 \%$ & $6.860 *$ \\
\hline & $80 \%$ & -3.580 \\
\hline & $90 \%$ & $-7.140 *$ \\
\hline \multirow[t]{5}{*}{$65 \%$ humidity } & MMA & $-29.540 *$ \\
\hline & $60 \%$ & $-8.180 *$ \\
\hline & $70 \%$ & -1.320 \\
\hline & $80 \%$ & $-11.760^{*}$ \\
\hline & $90 \%$ & $-15.320 *$ \\
\hline \multirow[t]{5}{*}{$70 \%$ humidity } & MMA & $-28.220 *$ \\
\hline & $60 \%$ & $-6.860 *$ \\
\hline & $65 \%$ & 1.320 \\
\hline & $80 \%$ & $-10.440 *$ \\
\hline & $90 \%$ & $-14.000 *$ \\
\hline \multirow[t]{5}{*}{$80 \%$ humidity } & MMA & $-17.780 *$ \\
\hline & $60 \%$ & 3.580 \\
\hline & $65 \%$ & $11.760 *$ \\
\hline & $70 \%$ & $10.440 *$ \\
\hline & $90 \%$ & -3.560 \\
\hline \multirow[t]{5}{*}{$90 \%$ humidity } & MMA & $-14.220 *$ \\
\hline & $60 \%$ & $7.140 *$ \\
\hline & $65 \%$ & $15.320 *$ \\
\hline & $70 \%$ & $14.000 *$ \\
\hline & $80 \%$ & 3.560 \\
\hline
\end{tabular}

Note: $\left.{ }^{*}\right)$ : significant difference at $\alpha=0.05$ 
ANOVA test was used to know the influence of humidity towards chemical bonds between MMA and dentin collagen. There was a significant difference among the experimental groups $(\mathrm{p}<0.05)$. Turkey-HSD test was done to give evidence of distinctions for every experimental group. Peak value of the MMA carbonyl absorbance band among the experimental groups at $60 \%, 65 \%$, and $70 \%$ humidity showed significant difference $(\mathrm{p}<0.05)$. There was no significant difference $(\mathrm{p}>0.05)$ between $80 \%$ and $90 \%$ humidity in experimental groups. Experimental groups with $70 \%$ humidity compared with $60 \%, 80 \%$ and $90 \%$ humidity showed significant difference $(\mathrm{p}<0.05)$ and if compared with $65 \%$ humidity showed no significant difference $(\mathrm{p}>0.05)$. Furthermore, in experimental group with $90 \%$ compared with $60 \%, 65 \%$, and $70 \%$ humidity showed significant difference $(\mathrm{p}<0.05)$, but not for $80 \%$ humidity $(\mathrm{p}>0.05)$.

\section{DISCUSSION}

Infra red spectrum also can be used to count the quantitative value of the ofmixing matter components. However the number of each factor definitely must be calculated accurately in order to get accurate and trustworthy datas.

If collagen fiber mixes with MMA, chemical reaction between amino group of collagen and esther carbonyl group of MMA will occur. In fact, not all of the esther carbonyl group of MMA fully reacted with amino collagen groups. This matter can be seen at peak of the mixture of MMA carbonyl and amino collagen absorbance band which is decrease but not disaper. Esther carbonyl wave number $\left(\dot{v}_{\mathrm{C}=\mathrm{O}}\right)$ absorbance ranging around 1700 to $1750 \mathrm{~cm}^{-1}$.

In this research, the peak of esther carbonyl at MMA absorbance band is used as the control or comparison with the peak of esther carbonyl absorbance band at experimental groups by various kind of humidity treatments. If many carbonyl groups at MMA react with amino collagen groups, the IR ray spectrum will occur the reduction of peak of the mixture of esther carbonyl at MMA and collagen absorbance band. So it can be assumed that if there is great reduction of peak of the MMA carbonyl absorbance band, it means that will be there are many esther carbonyl groups bond with amino groups. This means that chemical bond between MMA and collagen can be stronger than ever.

Chemical bond between bonding agents MMA based and collagen fibril should be considered even though from the previous research chemical bond only $30 \%$ compared with physical-mechanical bond strength. The chemical bond strength depends on the condition of surrounding collagen, such as humidity and temperature. ${ }^{5,19}$ The study used constant temperature $\left(25 \pm 2{ }^{\circ} \mathrm{C}\right)$. At an optimum humidity, the condition of collagen fibril is very permeable, not only made a strong bonding between MMA carbonyl group and collagen amino group, but also a maximum hydrogen bond inside molecule chain, or among collagen molecules. Moreover a good penetration of MMA into nano interfibriler space will occur and polymerization of MMA will form a mechanical retention.

If the humidity of surrounding dentin is too high, MMA solution difficult to react with collagen fibril, because many water molecules in surrounding fibril will block the MMA penetration. An excessive hydrogen bond between water molecule and dentin collagen made bonding between collagen molecule and MMA can not chemically occur. Reis et $a l .{ }^{20}$ reported that the use of air stream is not effective to remove water from mixture of bonding agents and water. The location of the highest water concentration is predicted in the deepest collagen fibril (profunda site), so it is difficult to remove water using air stream and the bonding agents is difficult to diffuse. A study of MicroRaman Spectroscopy showed that monomer concentration decrease from the upper side to hybrid layer base which formed by adhesive resin. For example, bonding agents concentration will decrease almost $55 \%$ at $2 \mu \mathrm{m}$ under surface region and decrease almost $21 \%$ at hybrid layer base. But if the surrounding dentin is very dry (minimum humidity) the collagen will collapsed. It will make the hydrogen chain of inter and intra molecule collagen are broken and collagen amino group are covered with remain of collagen fibril. The condition not only makes amino collagen groups can not react with MMA carbonyl groups, but also interaction between functional groups of MMA and fungtional group (carboxylate, amino, amide) collagen do not occur and no complex reaction between $\mathrm{Ca}^{++}$dentin and MMA. It has been reported that in water free region (dry area), the polymer chain formation is weaker and unstable. The $\mathrm{pH}$ of monomer solution plays role in chemical bond strength between bonding agent and collagen. ${ }^{22}$ The experiment, proved that high bonding strength between HEMA and collagen occur at $\mathrm{pH}$ 2. If $\mathrm{pH}$ rise up to 6.6, the bonding strength will decrease. However if $\mathrm{pH}$ is rise from $\mathrm{pH} 9.0$ to 12.5 , the bonding strength will increase again. Bonding strength is studied using method of collagen functional groups dissociation, such as, carboxylate and amino. If carbocylate acid dissociation or amino group is being inhibited. the hydrogen bond between resin and collagen will increase. If $\mathrm{pH}$ of collagen suspension is low, carboxylate acid will not be dissociated, so the interaction of resin and collagen will increase. The $\mathrm{pH}$ of MMA solution in the study was 5.0.

Nakabayashi and Pashly ${ }^{5}$ reported that the process of collagens collapse known as passive theory. Passive theory is demineralized collagen network will float or suspended in water. Each fibril will be separated one another by water molecule in the space between fibril. Prior to water molecule the space is filled by apatite crystal. At drainage process, the water which supports collagen network will be eliminated, collagen will close and aggregate three dimensionly. This condition is called collapse or shrinkage. The fibril bonding becoming stiff and creating the interfibriler hygrogen bond which interact electrostatically or hydrophobically. ${ }^{5}$ Water additional changed the condition into passive 
re-expand. Water molecule can periform hydrogen bond with collagen peptide, breaking interfebriler hydrogen bond so the collagen network is re-expand. The re-expand network functions as hydrogel, where water osmotically entering interfibriler space.

In this research, pure MMA solution is used to examine role of MMA on chemical bond to pure collagen. Mean of band's peak of the MMA carbonyl absorbance is 48.7 \pm 3.7 , this value decrease at $60 \%$ humidity $(27.3 \pm 2.2)$; $65 \%$ humidity (19.1 \pm 1.7$) ; 70 \%$ (20.5 \pm 1.3$) ; 80 \%$ (30.9 $\pm 1.5)$ and $90 \%(34.5 \pm 3.1)$. The lower the band's peak value of the MMA carbonyl absorbance the greater the bonding of MMA carbonyl groups to collagen amino groups. It makes the bonding strength between two agents increase. The highest strength of chemical bonds occur at $65 \%$ humidity, since the water molecule surrounding around fibril in optimum condition. Water molecule makes collagen re-expand, and collagen become more active and permeable to MMA. Comparing with previous research, the bond strength of bonding agents HEMA based and MMA based are different. The highest bonding strenght of HEMA based, is at $70 \%$ humidity, while bonding agent MMA based is at $65 \%$ humidity. It may be caused by the difference of agent density. HEMA's density is $1.07 \mathrm{~g} / \mathrm{ml}$ while MMA density is $0.945 \mathrm{~g} / \mathrm{ml}$.

Table 1 showed that mean of the band peak's value of MMA carbonyl absorbance from $60 \%$ to $90 \%$ humidity are significantly increase. It caused chemical bond strength decrease. The increase of humidity makes water molecules surround fibril rise and the penetration of MMA solution to collagen fibril is blocked. If we compare the $65 \%$ and $60 \%$ humidity, chemical bond strength at $65 \%$ humidity is higher than $60 \%$, since at $60 \%$ humidity, the condition of fibril is drier, so as the results fibril collapsed and low chemical interaction between MMA and collagen occur.

The research suggest that maximum chemical bond strength between MMA carbonyl groups and amino collagen groups occur at optimum humidity of $65 \%$.

\section{REFERENCES}

1. Accorinte MLR, Loquercio AD, Reis A, Muench A. Adverse effect of human pulps after direct pulp-capping with the different components from a total etch, three step adhesive system. Dent Mat $2005 ; 21: 599-607$.
2. Summitt JB, Robbins JW, Hilton TJ, Schwartz R. Fundamentals of operative dentistry. $3^{\text {rd }}$ ed. Chicago: Quintess Publ Co, Inc; 2006. p. 183-242.

3. Anusavice KJ. Phillip's science of dental materials. $11^{\text {th }}$ ed. Philadelphia: WB Saunders Co; 2003. p. 21-395.

4. Craig RG, Powers JM, Wataha JC. Dental materials. Properties and manipulation. $8^{\text {th }}$ ed. Baltimore, Boston, Carlsbad: Mosby Inc; 2002. p. 57-78.

5. Nakabayashi NP, Pashley DH. Hybridization of dental hard tissues. $1^{\text {st }}$ ed. Chicago IL: Quintess Publ Co, Ltd; 1998. p. 1-107.

6. Brackett MG, Brackett WW, Haish LD. Microleakage of class V resin composites placed using self-etching resins. Quintess Int 2006; 37:109-13.

7. Xu J, Stangel I, Butler IS, Gilson DFR. An FT Raman Spectroscopy Investigation of dentin and collagen surfaces modified by HEMA. J Dent Res 1997; 76:596-601.

8. Carrilho MR, Tay FR. Pashley DH. Mechanical stability of resindentin bond components. Dent Mat 2005; 21:232-41.

9. Cohen S, Burns RC. Pathways of the pulp. $8^{\text {th }}$ ed. St Louis, London, Philadelphia: Mosby Inc; 2002. p. 411-54.

10. Nishiyama N, Asakura T, Suzuki K. Adhesion mechanism of resin to etched dentin primed with N-MGly studied by ${ }^{13} \mathrm{C}$ NMR. J Biomed Mater Res 1998; 40:458-63.

11. Nishiyama N, Asakura T, Suzuki K, Komatsu K. Bond strength of resin to acid-etched dentin studied by ${ }^{13}$ NMR. J Dent Res 2000; 79:806-11.

12. Perdigao J, Lopes M. The effect of etching time on dentin demineralization. Restorative Dent 2001; 32:19-26.

13. Breschi L, Gobbi P, Marzotti G, Falconi M. High resolution SEM evaluation of dentin etched with maleic and citric acid. Dent Mat 2002; 18:26-35.

14. Finger WJ, Tani C. Effect of relative humidity on bond strength of self-etching adhesive to dentin. J Adhes Dent 2002; 4:277-82.

15. Zohairy AA, De Gee AJ, Mohsen M. Effect of conditioning time of self-etching primers on dentin bond strength of three adhesive resin cements. Dent Mat 2005; 21: 83-93.

16. Frankenberger R, Tay FR. Self etch vs etch-and-rinse adhesive: effect of thermo-mechanical fatique loading on marginal quality of bonded resin compositerestorations. Dent Mat. 2005; 21:397-412.

17. Soetojo A. Kekuatan perlekatan antara bahan bonding HEMA dengan kolagen dentin pada berbagai kelembaban. Disertation. Surabaya: Airlangga University; 2006. p. 66-9.

18. Kemp W. Organic spectroscopy. $2^{\text {nd }}$ ed. Edinburgh: ELBS/Macmillan Ltd; 1988. p. 12-81.

19. Noort RV. Introduction to dental materials. $2^{\text {nd }}$ ed. Edinburgh, London, New York, Oxford: CV Mosby Co; 2002. p. 11-78.

20. Reis A, Alessandro D, Loguercio, Carvalho RM, Grande RHM. Durability of resin dentin interface: effects of surface moisture and adhesive solvent component. J Dent Mat 2004; 20:669-76.

21. Renzo MD, Ellis TH. Chemical reactions between dentin and bonding agents. J Adhesion 1994; 47:115-21.

22. Nishiyama N, Suzuki K, Nagatsuka A, Nemoto K. Dissociation states of collagen functional groups and their effects on priming efficacy of HEMA bonded to collagen. J Dent Res 2003; 82:257-61. 